\title{
MANUALLY OPERATED SHEET ROLLING MACHINE
}

\author{
Shivam Patel ${ }^{1}$, Piyush Baviskar ${ }^{2}$, Ketan M. Patel $^{3}$ \\ ${ }^{1}$ Student, Department of Mechanical Engineering SAL Institute of Technology and Engineering Research, Sola Bhadaj \\ Road, Opposite Science City, Sola Village, Ahmedabad, Gujarat 380060 \\ ${ }^{2}$ Student, Department of Mechanical Engineering SAL Institute of Technology and Engineering Research, Sola Bhadaj \\ Road, Opposite Science City, Sola Village, Ahmedabad, Gujarat 380060 \\ ${ }^{3}$ Assistant Professor, Department of Mechanical Engineering SAL Institute of Technology and Engineering Research, \\ Sola Bhadaj Road, Opposite Science City, Sola Village, Ahmedabad, Gujarat 380060
}

\begin{abstract}
The global drive toward intermediate technology and sustainable development motivated the development of sheet metal rolling machines for small-scale artisanal manufacturers. Hence, aim of our project to develop and design a portable sheet bending machine which is useful to bend a sheet into cone and cylinder shape. It reduces human effort and also requires less skill to operate this machine. This machine works on simple kinematic system instead of complicated design. This machine can bend up-to 4-5mm thickness of sheet. Due to its portability it can be used by small workshop or fabrication shop. It is widely used in various industrial operations such as bending a sheet in required shape \& size. In this project, designing a portable sheet bending machine, our objective is to increase accuracy at low price without affecting the sheet bending productivity.
\end{abstract}

Keywords:-spur gear, capacity, bending load, metal rolling.

\section{INTRODUCTION}

Sheet metal creation assumes a vital part in a metal assembling world. Metal sheet is utilized as a part of the generation of materials extending from devices, to pivots, cars and so forth. Sheet metal manufacturing ranges from profound drawing, stamping, framing and hydro shaping, to high vitality rate framing (HERF) to make desired shapes from different purposes. Application of sheet metal is there in tool making, automobiles industries, boiler shell industries and many more. Sheet metal forming, consisting of deep drawing, forging, and hydro forming, to create desired shape. More easy and elegant shapes may be folded from a single plain sheet of material without stretching or machining, if shape of sheet metal is the bending continuously the piece along a linear axis, this causes alteration of the original form of the sheet as it passes through a path way of bottom rollers.

The present innovation relates to the plate bending machine which operates with rollers. Although there are many automated sheets rolling machines are presently available in market today, our aim was to design and develop such machine which is manually operated which can be used in small workshops with vey less cost.

\section{COMPONENTS USED IN MANUFACTURING}

[1] Three heavy solid rollers.

[2] Driving and driven gears.

[3] Frame and chassis.

[4] Side plate.

[5] Screw jack.

[6] Manually driven handle.

\subsection{Rollers}

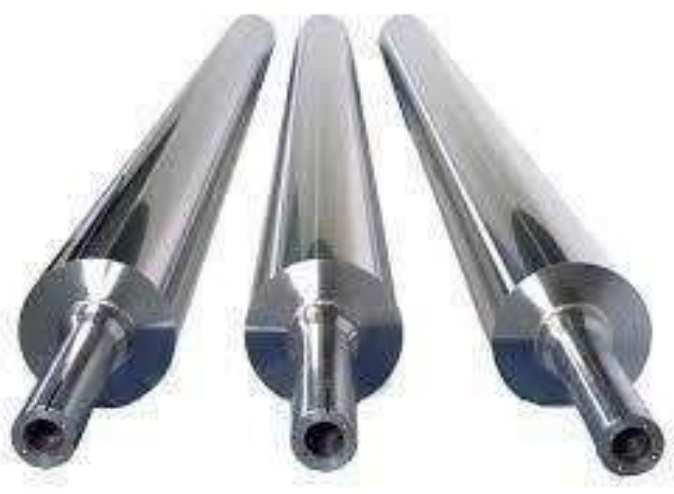

Fig -1: Rollers

The term shaft usually refers to the rotating machine elements, circular in shape which supports transmitting elements like gear, pulley and transmit power. Shafts are made from ordinary carbon steel and according to the capacity of the machine. Alloy steels are more expensive compared to the plain carbon steel but they are more ahead and serves the purpose to strength, hardness and toughness and are also corrosion resistant. In this machine we have used three rollers of which the upper roller has a diameter slightly larger than the other two rollers which helps to provide early static load to the metal sheet.

\subsection{Gears}

Gear are used to transmit torque and angular velocity in various different applications. There is also a wide variety of 
gears chosen according to transmit power and torque. The simplest type of gear, spur gear is designed to operate on parallel shaft and having teeth parallel to the shaft axis. Other types of gears such as helical, bevel, and worm can accommodate within non-parallel shafts.

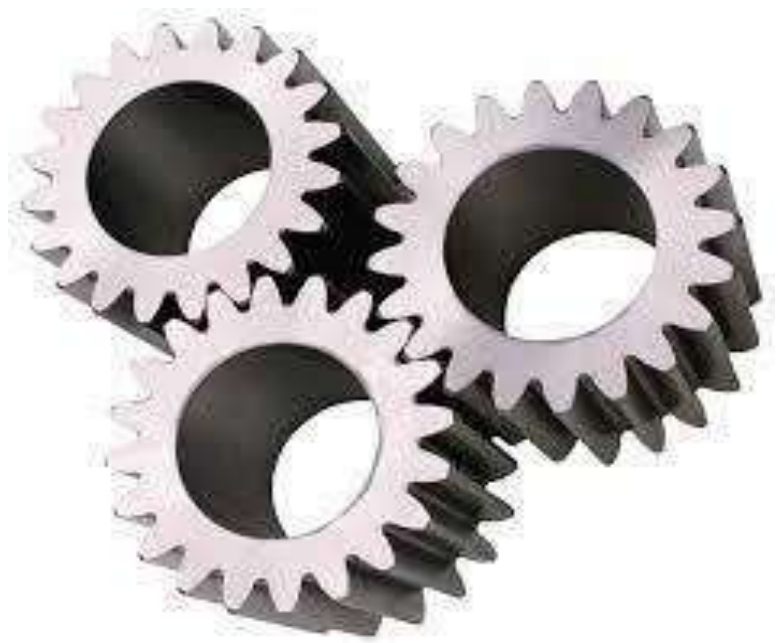

Fig -2: Gears

Table -1: MATRIC PROPERTIES OF MATERIAL

\begin{tabular}{|l|c|}
\hline \multicolumn{1}{|c|}{ PROPERTIES } & METRIC \\
\hline Tensile Strength & $690 \mathrm{MPa}$ \\
\hline Yield Strength & $580 \mathrm{MPa}$ \\
\hline Elastic Modulus & $190-210 \mathrm{GPa}$ \\
\hline Poisson's Ratio & $0.27-0.30 \mathrm{GPa}$ \\
\hline
\end{tabular}

\subsection{Screw Jack}

Screw jack is mechanical device which is used to convert a rotary motion in a linear motion as required. Lifting of any load, pushing or pulling of mechanical equipment, adjusting of tight clearance of mechanical parts can be done by screw jack. The screw thread on jack provides the screw jack a mechanical advantage. Capacity of screw jack is between $5 \mathrm{KN}$ to $2000 \mathrm{KN}$.

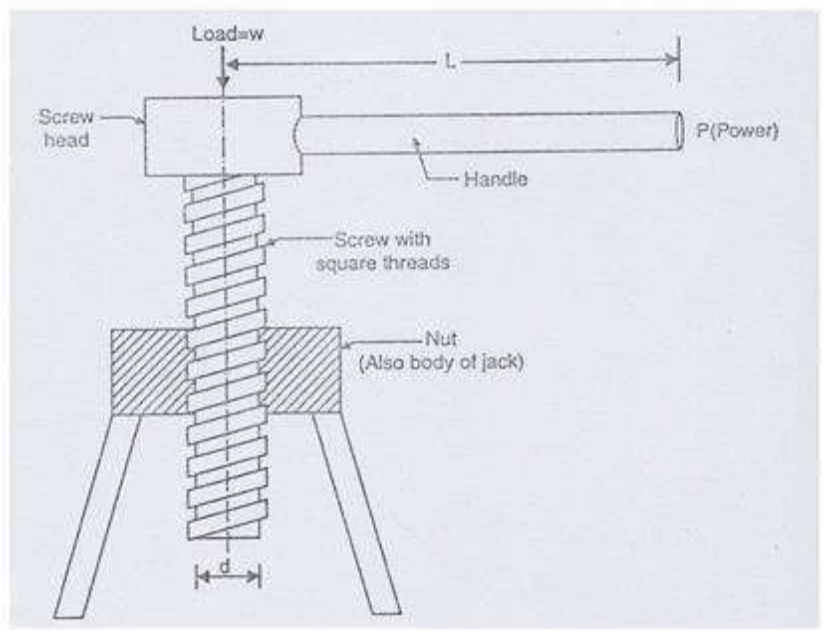

Fig -3: Screw Jack

\section{CALCULATIONS OF COMPONENTS}

\subsection{Design of Spur Gear}

Material $=$ EN8 (hardened and tempered)

$\mathrm{S}_{\mathrm{ut}}=550 \mathrm{n} / \mathrm{mm}^{\wedge} 2$

Module $(\mathrm{M})=3$

No. of teeth $(Z)=20$

Power $(\mathrm{P})=0.3 \mathrm{HP}=0.2237 \mathrm{~kW}$

Diameter $(\mathrm{D})=\mathrm{M} \times \mathrm{Z}=3 \times 20=60$

Bending strength $\left(\sigma_{b}\right)=\mathrm{S}_{\mathrm{ut}} / 3$

$=550 / 3$

$=183.33 \mathrm{~N} / \mathrm{mm}^{2}$

Addendum of gear (ha) $=1 \times \mathrm{M}$

$$
=1 \times 3=3 \mathrm{~mm}
$$

Dedendum of gear $(\mathrm{hf})=1.25 \times \mathrm{M}$

$$
=1.25 \times 3=3.75 \mathrm{~mm}
$$

Total tool height $(\mathrm{h})=\mathrm{ha}+\mathrm{hf}$

$$
=3+3.7=6.75 \mathrm{~mm}
$$

Lewis's form factor $(Y p)=0.484-2.87 / 20$

$$
=0.3405
$$

Beam strength of material $=\mathrm{M} \times \mathrm{b} \times \mathrm{Yp}$

$$
\begin{aligned}
& =183.33 \times 3 \times 30 \times 0.3405 \\
& =5618.15 \mathrm{~N} / \mathrm{mm}^{2}
\end{aligned}
$$

Velocity $(\mathrm{v})=\pi \times D \times N(/ 60 \times 1000)=$ $(3.14 \times 60 \times 15 / 60,000)=0.04714 \mathrm{~m} / \mathrm{s}$

Tangential tooth load $(\mathrm{Ft})=\mathrm{P} / \mathrm{V}$

$$
=(0.2237 \times / 0.04714)=4745.439 \mathrm{~N}
$$

So, $\mathrm{Fb}>\mathrm{Ft}$ our design is safe.

Torque $(\mathrm{T})=(\mathrm{P} \times 60) /(2 \times \pi \times \mathrm{N})$

$=(0.2237 \times 103 \times 60) /(2 \times 3.14 \times 15)=142.484 \times 10^{3}$ N.mm

Tooth thickness $=1.5708 \times \mathrm{M}=4.7124 \mathrm{~mm}$

Minimum clearance $=0.25 \times \mathrm{M}$

$$
=0.75 \mathrm{~mm}
$$

Fillet radius of root $=0.4 \times \mathrm{M}$

$$
=1.2 \mathrm{~mm}
$$

\subsection{Design of Top Roller}

\author{
Material $=\mathrm{EN} 8$ \\ Sut $=550 \mathrm{~N}$ \\ $\mathrm{P}=0.2237$ \\ $\mathrm{T}=142.484$ N.mm \\ $\mathrm{FT}=4745.439 \mathrm{~N} / \mathrm{mm}$ \\ $\mathrm{FT}=2 \mathrm{~T} / \mathrm{D}$ \\ $\mathrm{D}=2 \times 142.484 \times 103 / 4745.439$ \\ $=65 \mathrm{~mm}$ (approx.)
}




\section{Maximum Cell Diameter \\ $\mathrm{D}=10 \times$ top roller diameter \\ $=10 \times 65$ \\ $=650 \mathrm{~mm}$}

Length of Required Sheet

$=\pi \mathrm{r}+5$

$=3.14 \times 325+5$

$=1030 \mathrm{~mm}$ (approx.)

\section{AIMS AND OBJECTIVES}

To minimize the overall machine cost of it with it it's directly proportional to the effective efficiency of the machine.ROI (Return of Investment) of machine is recovered in $1 / 2$ years of time period. It has the simple design with every property checked in the machinelikevibration factors and balancing of it.

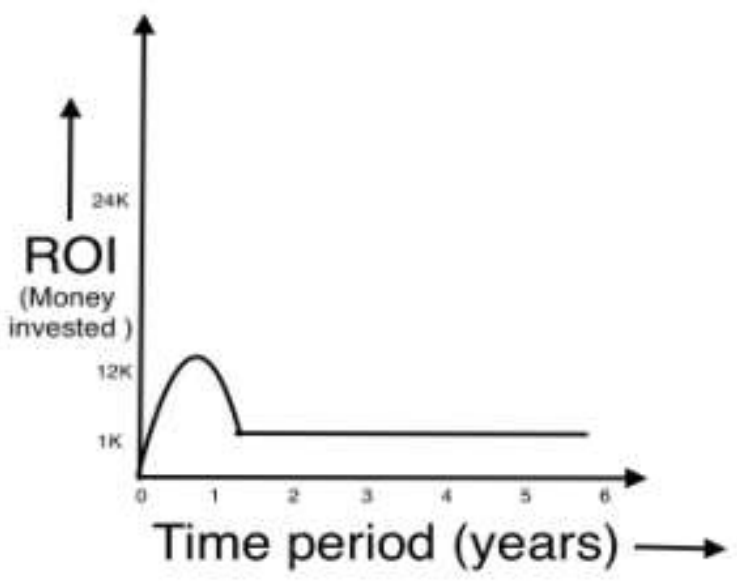

Fig-4: ROI of Machine

\section{PIPE BENDING PROCESS}

A pipe bending is a process of bending pipe with the help of attached fixtures on one end of the rollers. A pipe is placed in the main frame and fixed to the bending arm by a clamp. The bending arm is initially placed at the front of the bending machine. The pusher then pushes the pipe forward, which results in a rotation of the bending arm. This introduces a high bending moment in the clamp.

The following points also need to be taken into account: [1] The shape of the pipe to be bent (round-section squaresection, etc.).

[3] The outside diameter "D" of the pipe.

[4] The wall thickness "S" of the pipe.

[6] The required bending angles.

[7] Details of the length "L" of the overall pipe.

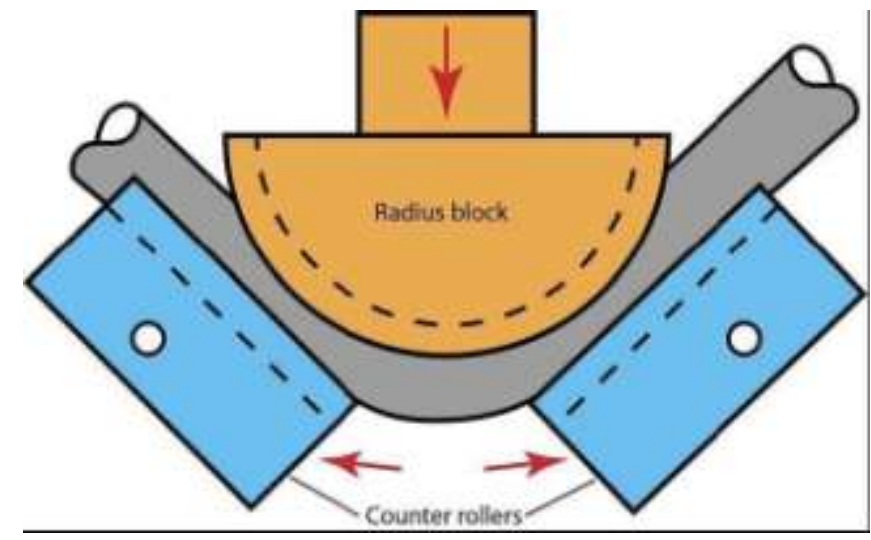

Fig -5: Bending of pipe

\section{FUTURE SCOPE}

It can be used in any machine parts where sheet rollers are required. In commercially to make household things to, it can drums of grain storage, fending, gate or wall light. This it has various scope for future with a less initial cost same productions.

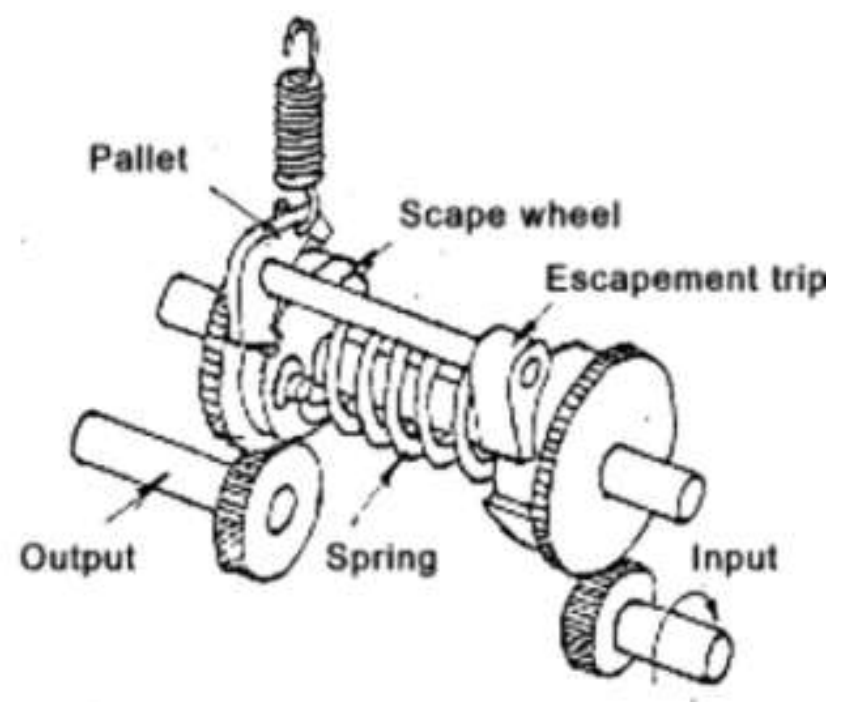

Fig 6

\section{WORKING}

After keeping roller steady insert 3 to $5 \mathrm{~mm}$ sheet after that by screw adjust their height. Then accordingly rotate the handle and after some pick time inject the screw roll $2 / 3$ rotation and again the same process by this we will get a fine rolled sheet.

\section{FUTURE UPGRADATION}

As we all know that up gradation is the best way to reduce human efforts. To reduce the human efforts and increase the accuracy of the machine we have planned to add a spring loaded mechanism which is used in toy car or key locks so it would be the best way to upgrade with less cost and with same output efficiency or more. 


\section{CONCUSION}

Although there are high speed automated sheet rolling machines are available in the market which are more efficient than this manually operated machine but the cost of such machine is very high and small workshop owner cannot afford such costly machines and also automated machines occupies more floor space. Hence main purpose of this concept is make such a machine which everyone can afford and which canbe used anywhere even in small scale workshop and accommodated in small space and it works without affecting the efficiency and performance. Another advantage is as it is manual so it does not rely on electric supply .

\section{REFERNCES}

[1] Aniruddha Kulkarni, Mangesh Pawar, Pravin Yadav, Amit Patil, Sohan Jagtap, "SHEET METAL BENDING MACHINE”,IJERT, vol.4, p135- 140, June2013.

[2] P.S. Thakare, P.G. Mehar, Dr. A.V. Vanalkar, Dr.C.C. Handa,"PRODUCTIVITY ANALYSIS OF MANUALLY OPERATEDAND POWER OPERATED SHEET BENDING MACHINE: A COMPARATIVE STUDY", IJERT, VOL.2, P15-32, July2014.

[3] Mr. Nitin P. Padghan, Mr. Prafulla D. Deshpande, Dr. C. N. Sakhale, "Force Analysis of Metal Sheet in Bending Operation on Sheet Bending Machine",IJERT, VOL 3, January2015.

[4] Nilesh W. Nirwan, Prof. A. K. Mahalle, "Design and Analysis of Portable Rolling and Bending Machine Using CAD and FEA Tool',IJERT, VOL. 2, April2014.

[5] R.S. Bello, "Development and evaluation of metal rolling machine for small scale manufacturers", IJERT, VOL.1, May2013. 